\title{
Deleterious EGFR Gene Mutation
}

National Cancer Institute

\section{Source}

National Cancer Institute. Deleterious EGFR Gene Mutation. NCI Thesaurus. Code

C150500.

A change in the nucleotide sequence of the EGFR gene that is associated with increased risk of disease. 